\title{
SPECTRAL PROPERTIES BETWEEN OPERATOR MATRICES AND HELTON CLASS
}

\author{
Ji EUN LEE
}

Abstract. In this paper, we study properties of Helton class of an operator matrix. In particular, we show that some upper operator matrix belongs to Helton class of an operator matrix have the property $(\beta)_{\varepsilon}$. As an application, we get that such operators have nontrivial invariant subspaces. Finally, we prove that Helton class preserves the generalized Weyl's theorem under some conditions.

Mathematics subject classification (2010): Primary 47A11, 47A53; secondary 47A10.

Keywords and phrases: Helton class, operator matrix, the property $(\beta)_{\varepsilon}$, the generalized Weyl's theorem.

\section{REFERENCES}

[1] C. P. AIENA, Fredholm and local spectral theory with applications to multipliers, Kluwer Academic Pub., 2004.

[2] M. Amouch And H. ZGuitti, On the equivalence of Broweder's and generalized Browder's theorem, Glasgow Math. J. 48 (2006), 179-185.

[3] P. Aiena, M. L. Colas ante, And M. GonzA' Lez, Operators which have a closed quasi-nilpotent part, Proc. Amer. Math. Soc., 2002.

[4] M. BERKANI, On a class of quasi-Fredholm operators, Int. Eq. Op. Th. 34 (1999), 244-249.

[5] I. COlOJOARA AND C. FoiAs, Theory of generalized spectral operators, Gordon and Breach, New York, 1968.

[6] L. A. Fialkow, A note on quasisimilarity of operators, Acta Sci. Math. (Szeged) 39 (1977), 67-85.

[7] J. W. Helton, Operators with a representation as multiplication by $x$ on a Sobolev space, Colloquia Math. Soc. Janos Bolyai 5, Hilbert Space Operators, Tihany, Hungary (1970), 279-287.

[8] Young Min Han And Ji Eun LeE, Local Spectral Properties for the Helton class of an operator, Filomat 24, 3 (2010), 83-93.

[9] J. EsChMEIER AND M. PUtinar, Spectral decompositions and analytic sheaves, LMS 10, Oxford Sci. Pub., 1996.

[10] J. EschmeIER, Invariant subspaces for subscalar operators, Arch. Math. 52 (1989), 562-570.

[11] H. ElbJaoui And E. H. Zerouali, Local spectral theory for $2 \times 2$ operator matrices, Int. J. Math. Math. Sci. 42 (2003), 2667-2672.

[12] Y. Kim, E. Ko, AND J. LEE, Operators with the single valued extension property, Bull. Kor. Math. Soc. 43 (2006), 509-517.

[13] Y. Kim, E. Ko, AND J. LEE, On the Helton class of p-hyponormal operators, Proc. Amer. Math. Soc. 135 (2007), 2113-2120.

[14] Y. Kim, I. Kim, E. Ko, AND J. LEE, Some connections between an operator and its Helton class, J. Math. Anal. Appl. 340 (2008), 1235-1240.

[15] Y. KIm, I. Kim, E. Ko, And J. LEE, Some remarks on the Helton class of an operator, Bull. Korean Math. Soc. 46 (2009), 535-543.

[16] Y. KIM, I. KIM, E. Ko, AND J. LEE, Inherited properties through the Helton class of an operator, Bull. Kor. Math. Soc. 48 (2011), 183-195.

[17] K. Laursen and M. Neumann, An introduction to local spectral theory, Clarendon Press, Oxford, 2000. 
[18] Ji Eun LEE, The Helton class of operators and rank one perturbations of the unilateral shift, Ph. D. Thesis, Ewha Womans University, 2008.

[19] M. PUtInAR, Quasismilarity of tuples with Bishop's property ( $\beta$ ), Int. Eq. Op. Th. 15 (1992), 10471052.

[20] H. RadjaVi And P. Rosenthal, Invariant subspaces, Springer-Verlag, 1973.

[21] S. ZHANG, H. ZHANG, AND J. WU, Spectra of Upper-triangular operator Matrix, preprint.

[22] E. Zerouali And H. ZQuitti, Perturbation of spectra of operator matrices and local spectral theory, J. Math. Anal. and Appl. 324 (2006), 992-1005. 